\title{
Caldera structure inferred from gravity anomalies west of Nagamachi-Rifu Fault, Northeast Japan
}

\author{
Masao Komazawa ${ }^{1}$ and Masaaki Mishina ${ }^{2}$ \\ ${ }^{1}$ National Institute of Advanced Industrial Science and Technology, 1-1-1 Higashi, Tsukuba, Ibaraki 305-8567, Japan \\ ${ }^{2}$ Tohoku University, Aoba-ku, Sendai, Miyagi 980-8578, Japan
}

(Received January 25, 2002; Revised October 17, 2002; Accepted October 17, 2002)

\begin{abstract}
A gravity survey was conducted in and around the Nagamachi-Rifu Fault. The density for both terrain and Bouguer corrections was chosen to be $2,300 \mathrm{~kg} / \mathrm{m}^{3}$, because volcanic rocks are dominant over the whole measurement area and the surface layer density is estimated to be low from geological considerations. The Bouguer anomalies are characterized by a low anomaly similar to those of a caldera and the basement structure inferred from two and three-dimensional analysis shows that the depth is often more than $1 \mathrm{~km}$ in the caldera region and that there is a circular structure. The gradient of basement is steepest at the southern margin, and it resembles to rim of funnel-shaped caldera.
\end{abstract}

\section{Introduction}

A gravity survey was carried out in the vicinity of the Nagamachi-Rifu Fault, which is located in Miyagi Prefecture, northeastern Japan. The total number of measurement points was about 670 , and about 410 stations were at seismic survey points. The location and altitude were obtained from differential GPS with an accuracy of $1 \mathrm{~m}$ or several tencentimeter. These data were compiled together with about 6,700 existing data points to produce a gravity map. In this area there are some topographic depression structures resembling a caldera in the western part and the eastern part is flat, however, the underground structure, such as the thickness of the sedimentary layers or location of the active fault are not known. To investigate the underground structure this gravity survey was carried out in June and July 2001 and a seismic reflection survey was made at the same time (Ikawa et al., 2001).

\section{Gravity Survey Details}

Gravity meters used in this survey were LaCoste \& Romberg G-type (G-304 and G-579) and ZLS Burris (B001), which have been used for nation-wide gravity surveys. The gravity meters were calibrated using the Mt. Tsukuba Calibration Line. The position and altitude of the gravity stations were obtained using a Magellan differential GPS system. In addition, a TOMMEN barometric altimeter was used for real time checking of height. The position and altitude were determined with an accuracy of within $1 \mathrm{~m}$, or several centimeters at best, relative to a base station in the Japanese Gravity Standardization Net 1975 (JGSN75), which was established in Tohoku University by the Geographical Survey Institute (1976). A loop-closing method was used to enable

Copy right (C) The Society of Geomagnetism and Earth, Planetary and Space Sciences (SGEPSS); The Seismological Society of Japan; The Volcanological Society of Japan; The Geodetic Society of Japan; The Japanese Society for Planetary Sciences. corrections for gravity meter drift. The gravity base station was also established at the same site as that of GPS base station.

\section{Data Processing of the Measured Gravity Data}

All measured gravity data were referred to the International Gravity Standardization Net 1971 (IGSN71) (for example, Woollad, 1979) and normal gravity values were calculated according to the Geodetic Reference System 1980 (GRS80). Bouguer corrections were made in a circular region within a radius of $60 \mathrm{~km}$ in arc-distance using a spherical cap crust formula. Terrain corrections were also made for the same region by approximating the real topography to an assemblage of annular prisms derived from the elevation data of DEM (two kinds of digital elevation models: KS-110 (250 m mesh) and $50 \mathrm{~m}$ DEM by Geographical Survey Institute) and the gravity stations (Komazawa, 1988). The effect of the Earth's curvature was taken into consideration.

\section{Bouguer Gravity Anomalies}

The density for both the terrain and the Bouguer corrections was taken to be $2,300 \mathrm{~kg} / \mathrm{m}^{3}\left(2.3 \mathrm{~g} / \mathrm{cm}^{3}\right)$, because sedimentary and volcanic rocks and pyroclastic flows are distributed over the survey area, and the surface layer density is estimated to be about $2,300 \mathrm{~kg} / \mathrm{m}^{3}$ from experience. Bouguer anomaly maps with an assumed density of $2,300 \mathrm{~kg} / \mathrm{m}^{3}$ were drawn (Figs. 1 and 2) from the grid data and were obtained by interpolation using two-dimensional quadratic polynomials with distance-dependent weights, which are defined so as to fit the local surface. The two-dimensional curved surface thus obtained is continuous to both first and second derivatives in both the $x$ and $y$ directions, and is visually smooth. A regional gravity anomaly map of the whole survey area is shown in Fig. 1, and a map of the central part containing a caldera-like structure is shown in Fig. 2. A feature of these Bouguer anomaly maps is the low anomaly 


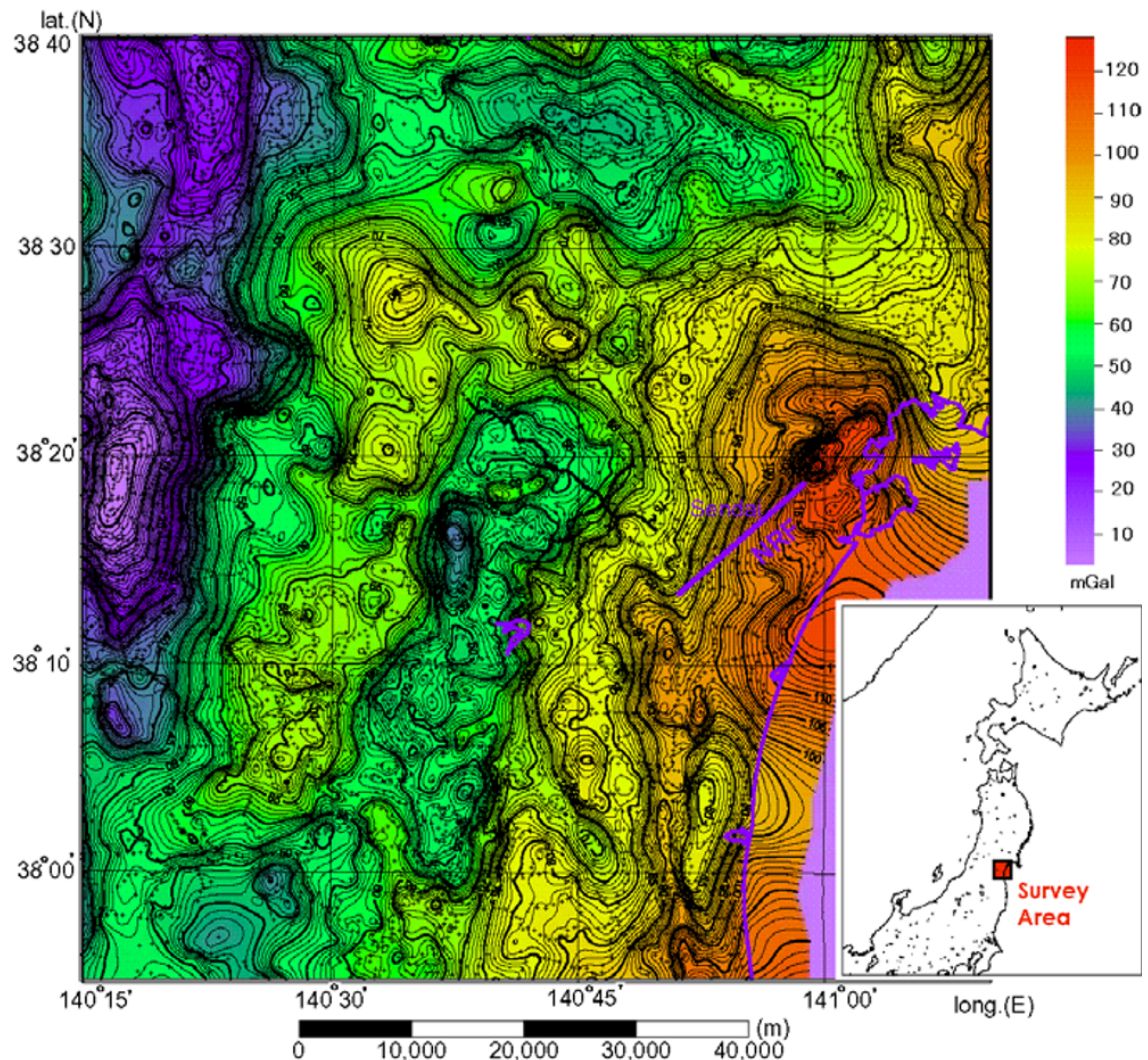

Fig. 1. Regional Bouguer anomalies with an assumed density of $2,300 \mathrm{~kg} / \mathrm{m}^{3}\left(2.3 \mathrm{~g} / \mathrm{cm}^{3}\right)$. Contour interval is $10 \mu \mathrm{N} / \mathrm{kg}(1 \mathrm{mGal})$. NRF denotes the Nagamachi-Rifu Fault. Gravity stations are shown with cross marks.

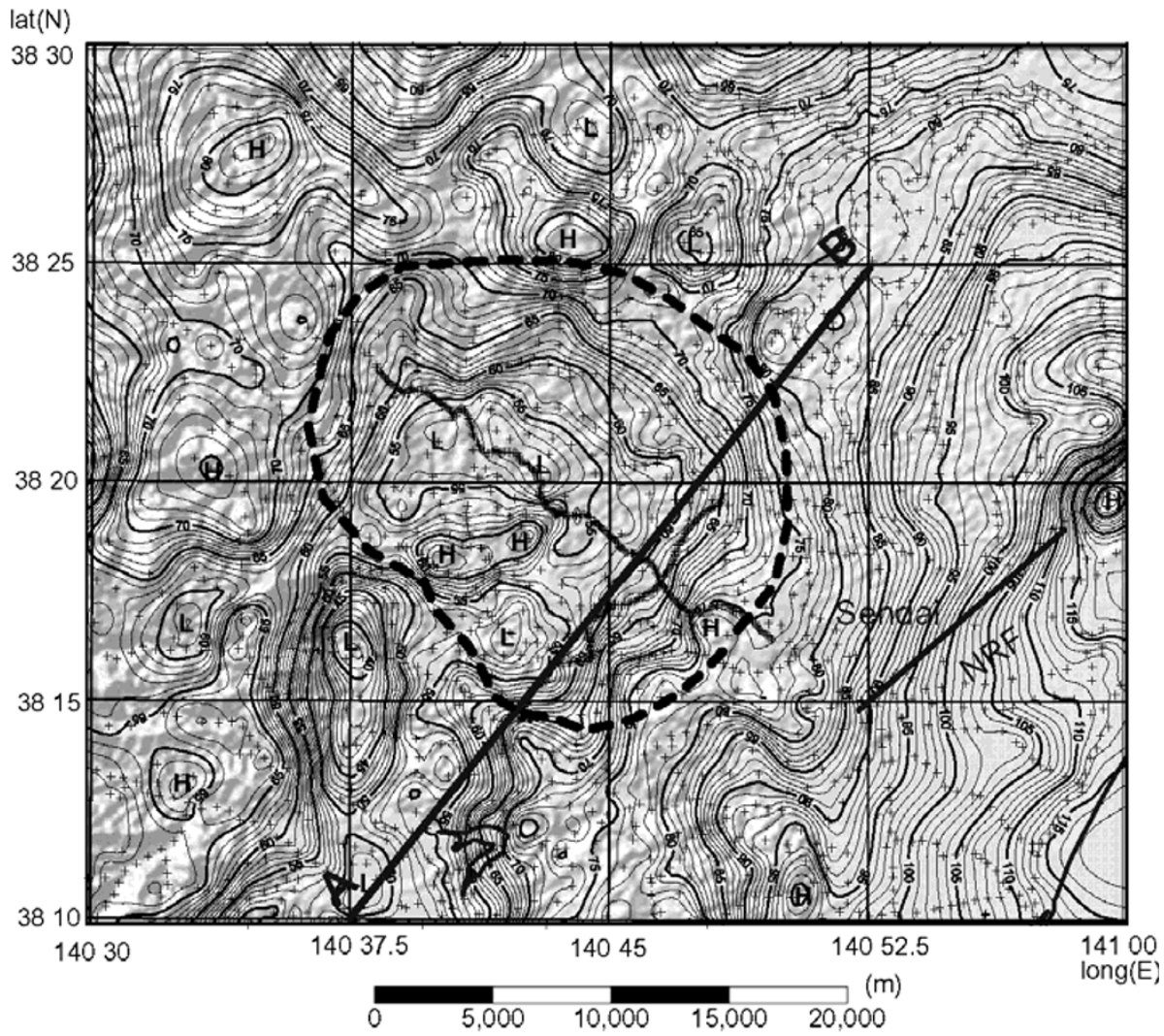

Fig. 2. Bouguer anomalies same as Fig. 1, but showing local Bouguer Anomalies. Line A-B indicates the location of the two-dimensional gravity analysis. The result of crustal modeling is shown in Fig. 3. Relief is topography and made from KS-110 (250 m digital elevation model). A circular dotted line denotes a caldera estimated from gravity data. 

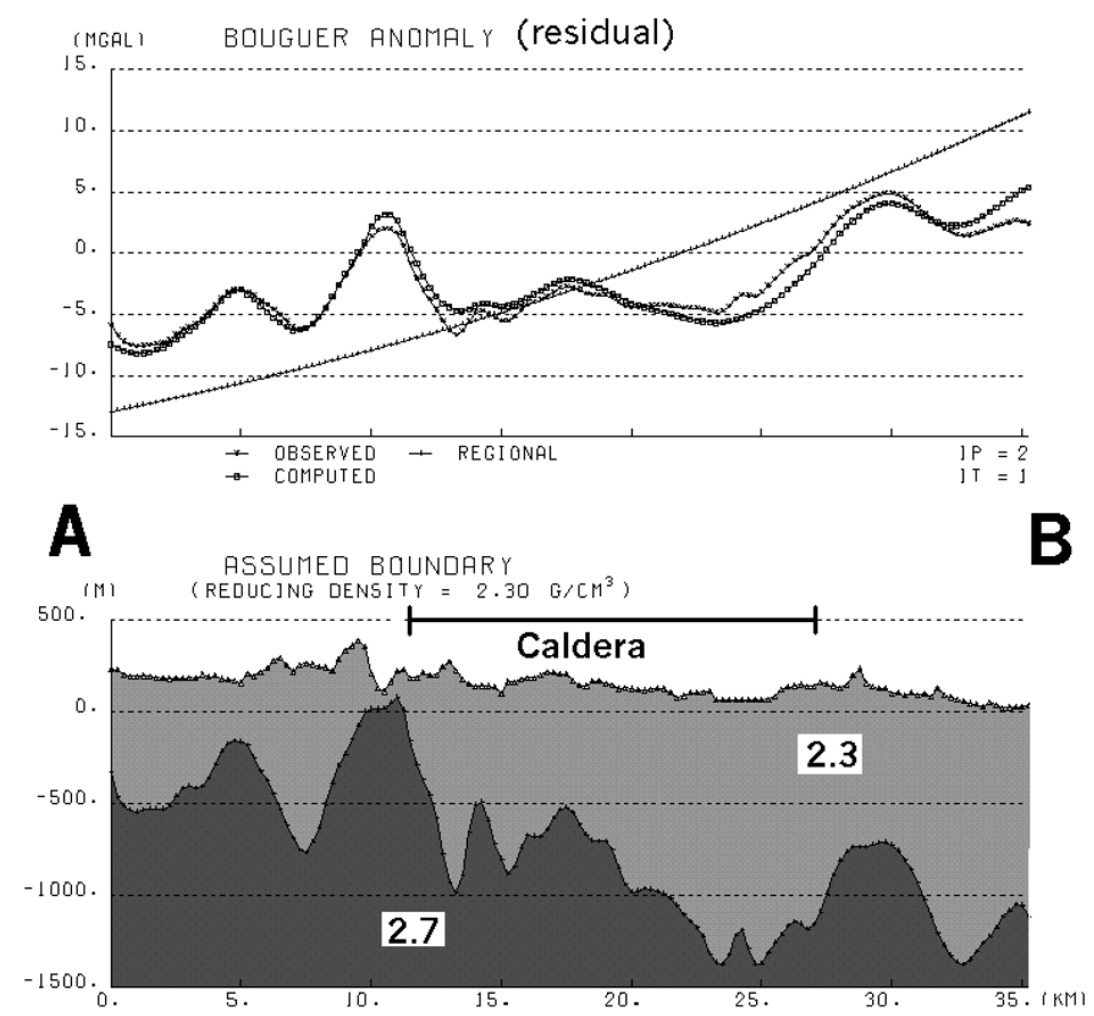

Fig. 3. Two-dimensional two-layered analysis. Bouguer gravity profiles (top) and crustal cross section (bottom) along line A-B inferred. Density contrast is $400 \mathrm{~kg} / \mathrm{m}^{3}\left(0.4 \mathrm{~g} / \mathrm{cm}^{3}\right)$. The location of the profile A-B is shown in Fig.2. Exaggeration of vertical direction horizontal is 7 times.
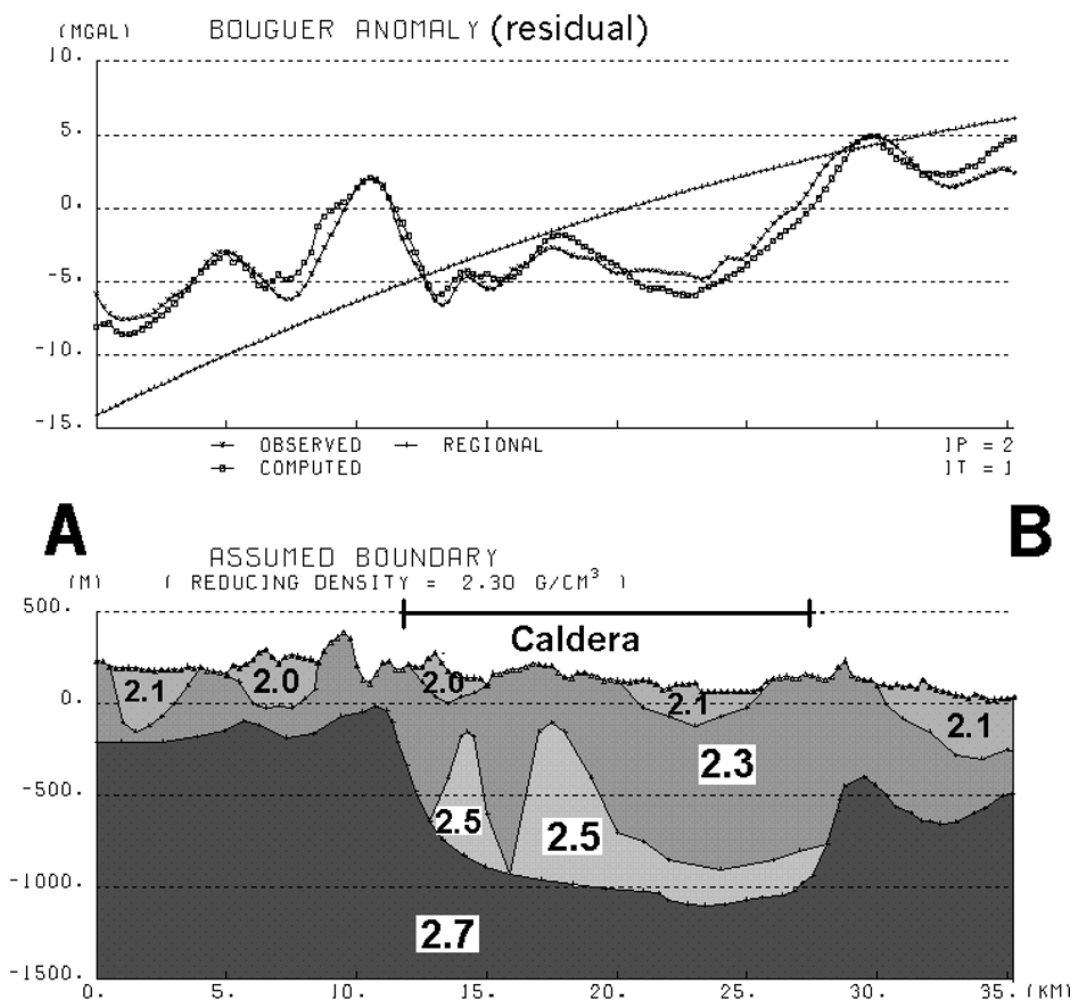

Fig. 4. Two-dimensional multi-layered modeling. Bouguer gravity profiles (top) and crustal cross section (bottom) along line A-B inferred. The values of model denote density in $1,000 \mathrm{~kg} / \mathrm{m}^{3}\left(\mathrm{~g} / \mathrm{cm}^{3}\right)$. The location of the profile A-B is shown in Fig. 2. Exaggeration of vertical direction horizontal is 7 times. 


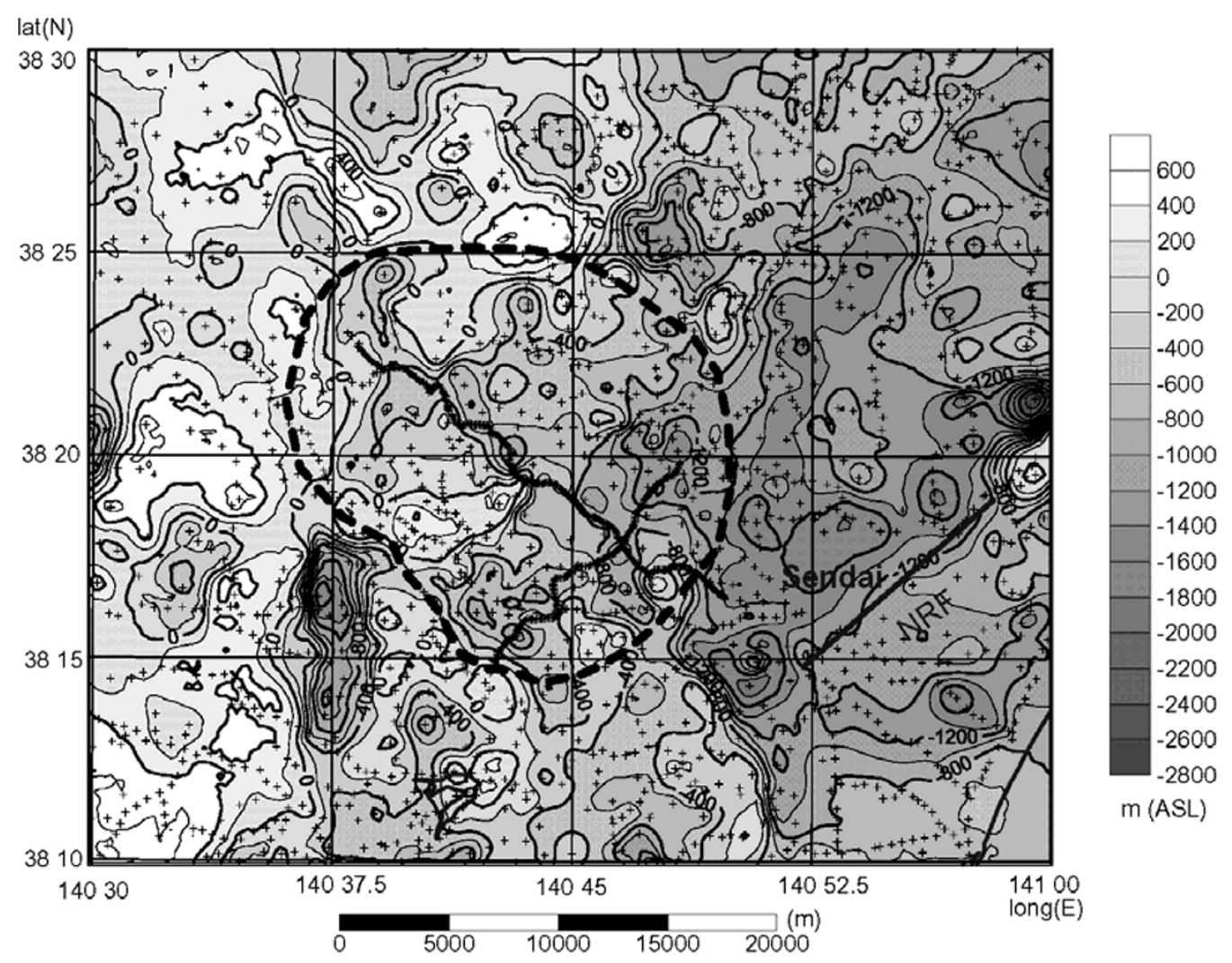

Fig. 5. Gravity basement in meter above sea level with density contrast of $400 \mathrm{~kg} / \mathrm{m}^{3}\left(0.4 \mathrm{~g} / \mathrm{cm}^{3}\right)$. Contour interval is $200 \mathrm{~m}$. NRF denotes the Nagamachi-Rifu Fault. Gravity stations are shown with cross marks. A circular dotted line denotes a caldera estimated from gravity data.

values, which suggest that the thickness of the sedimentary layer is more than $1 \mathrm{~km}$. The feature of Bouguer anomaly map corresponds to the geologic setting (Geological Survey of Japan, 1987), for example, that a dike structure within caldera shows clearly a high anomaly. But, the active fault, the Nagamachi-Rifu Fault, derived from the geologic consideration was not clear from the gravity anomalies.

\section{Basement Structure Inferred from Two and Three-Dimensional Analysis}

The two and three-dimensional analysis is based on the method by Komazawa (1995). Two-dimensional analyses was made on one profile (line A-B in Fig. 2), which corresponds to the NE-SW seismic reflection profiles (Ikawa et al., 2001), and the result is shown in Fig. 3. In this case, only an automatic analysis of a homogeneous model of two layers was made, without any geological constraints. It was assumed that the two layers were the basement bedrock and the sedimentary layer, and the density contrast between these two layers was $400 \mathrm{~kg} / \mathrm{m}^{3}$. The analysis shows that the maximum thickness of the sedimentary layer is about $1 \mathrm{~km}$ at the central area of low anomaly, a result similar to that of the seismic reflection survey (Ikawa et al., 2001). However, undulations of the basement might also result from near-surface density changes associated with shallow geological bodies such as volcanic units within the sediments (for example, Hunt, 1992). The small local gravity "low" at about $7 \mathrm{~km}$ along the profile line A-B is interpreted to generate a $500 \mathrm{~m}$ depression of the basement. The basement uplifts at 14 and $18 \mathrm{~km}$ are also likely to have similar alternative explanations.
An alternative (and probably more likely) explanation for the small local gravity "high" is that there is a dense volcanic mass (such as a resurgent dome, dike or post-caldera formation volcano) buried at shallow depth within the caldera, but which does not outcrop at the surface. Therefore, a multilayered modeling was conducted by taking the thickness of the low-density sediments, dense dikes and the empirical knowledge of volcanic geology into consideration, and the result is shown in Fig. 4. It is estimated that the bedrock (2.7) is granitic rocks and the buried high density rocks (2.5) is an assemblage of dikes related to extrusion sites of lava or metamorphic rocks, and that the low density of near-surface density is lake deposits or pyroclastic flows.

A three-dimensional gravity basement map was derived from the residuals of Bouguer anomalies, and the result is shown in Fig. 5. The residuals of Bouguer anomalies were obtained by a band-pass filter designed with two upwardcontinuation filters. Two parameters of this filtering method, upward-continuation heights, were $50 \mathrm{~m}$ and $2 \mathrm{~km}$, respectively. The parameter $50 \mathrm{~m}$ was adopted to remove the gravity effects of shallow inhomogeneous volcanic deposits within the sediments, whereas $2 \mathrm{~km}$ was adopted to remove the regional trend deeper than several kilometers from Bouguer anomalies. The basement depth was adjusted to match the ground surface in mountainous areas and the density contrast was assumed to be $400 \mathrm{~kg} / \mathrm{m}^{3}$. The basement map shows that the depth is often more than $1 \mathrm{~km}$ in the caldera region and that there is a circular structure in the basement. In this structure, the gradient of basement is steepest at the southern margin, and it resembles to rim of funnel- 
shaped caldera. The uplifted basement, extending from east and west in the southwest part of the caldera, corresponds to the high-density intrusion rocks.

\section{Conclusions}

A low anomaly with steep gradients, compared to those of thick sediment was found in the western area near the Nagamachi-Rifu Fault. However, the active fault derived from the geologic considerations was not clear from the gravity anomalies. A map of the gravity basement, derived from gravity data, shows that the basement depth is often more than $1 \mathrm{~km}$ in the caldera region, and the gradient of a circular structure is found and is interpreted to be the caldera rim. In order to obtain a better understanding of the subsurface structure, it is necessary to incorporate other geophysical and geological constraints such as seismic survey data, and information from drill holes.

Acknowledgments. The authors express their deepest appreciation to Dr. H. Ito of National Institute of Advanced Industrial Science and Technology for his assistance and useful information on this research project. The discussion with Dr. T. Yoshida of Tohoku University was valuable for caldera structure with gravity anomalies. The authors also thank two anonymous reviewers for valuable comments. And the authors would like to thank Dr. E. John Joseph of National Institute of Advanced Industrial Science and Technology and Akihiko Yamamoto of Hokkaido University for their specific readings and valuable comments.

\section{References}

Hunt, T. M., Gravity Anomalies, Caldera Structure, and Subsurface Geology in the Rotorua Area, New Zealand. Geothermics, 21, 65-74, 1992.

Ikawa, T., T. Kawanabe, S. Kawasaki, A. Hasegawa, N. Umino, A. Nakamura, H. Ito, T. Iwasaki, and H. Sato, Seismic reflection survey of the deep structure of Nagamachi-Rifu fault, Northeast Japan, Proceedings of International Symposium on Slip and Flow Processes in and below the Seismogenic Region, 301-308, 2001.

Geographical Survey Institute, Establishment of the Japanese Gravity Standardization Net 1975, J. Geod. Soc. Japan, 22, 65-76, 1976 (in Japanese with English abstract).

Geological Survey of Japan, Geological Map of Japan 1:200,000/SENDAI, 1987.

Komazawa, M., A gravimetric terrain correction method by assuming annular prism model, J. Geod. Soc. Japan, 34, 11-23, 1988 (in Japanese with English abstract).

Komazawa, M., Gravimetric analysis of Aso Volcano and its interpretation, J. Geod. Soc. Japan, 41, 17-45, 1995.

Woollad, G. P., The new gravity system - Changes in international gravity base values and anomaly values, Geophysics, 44, 1352-1366, 1979.

M. Komazawa (e-mail: komazawa-m@aist.go.jp) and M. Mishina 